\title{
Problem based Learning with Information and Communications Technology Support: An Experience in the Teaching-Learning of Matrix Algebra
}

\author{
Norka Bedregal-Alpaca ${ }^{1}$, Olha Sharhorodska ${ }^{2}$ \\ Victor Corneko-Aparicio ${ }^{4}$ \\ Departamento Académico de Ingeniería de Sistemas e \\ Informática, Universidad Nacional de San Agustín de \\ Arequipa, Arequipa, Perú
}

\author{
Doris Tupacyupanqui-Jaen ${ }^{3}$ \\ Departamento Académico de Matemáticas \\ Universidad Nacional de San Agustín de Arequipa \\ Arequipa, Perú
}

\begin{abstract}
Students and teachers face problems in the teaching-learning processes of matrix algebra, due to the level of abstraction required, the difficulty of calculation and the way in which the contents are presented. Problem-based Learning (PBL) arises as a solution to this problem, as it contextualizes the contents in everyday life, allows students to actively build that knowledge and contributes to the development of skills. The proposal describes a didactic sequence based on PBL, which uses cooperative techniques and MATLAB, as instruments that facilitate the resolution of problems close to the student experience. The features of the Moodle platform are used to support the face-to-face educational process. The perception of students, in relation to the activity shows that $83 \%$ believe that it contributed to the understanding of the topics covered and $79 \%$ think that it allowed them to develop their creativity and capacity for expression.
\end{abstract}

Keywords-Problem-based learning; cooperative techniques; constructionism; matrix algebra

\section{INTRODUCTION}

In 1850, J. Sylvester first used the term "matrix" and defined it as a rectangular arrangement of terms. Since then, matrix algebra has contributed to the development of many areas of knowledge: qualitative theory of differential equations, cryptography, mathematical optimization, decision theory, robotics, astronomy, etc.

The traditional way in which algebra is taught has resulted that many students finding it difficult to learn so they experience a rejection towards it, a rejection that is transferred to mathematics in general [1], [2]. It is necessary to consider, in the teaching-learning processes, consider situations in which the student can systematically move between the concrete and the abstract; so that algebraic concepts and processes make sense. In the problem experienced by the student, the level of abstraction required, the way in which the contents are presented, the lack of handling of the conceptual prerequisites (basic operations, rows, columns, variables, function) and the lack of contextualization with situations close to reality. In [3] and [4] it is proposed to use problem solving and project development as teaching-learning strategies in linear algebra courses.
Thus, Problem Based Learning (PBL) emerges as a solution to the problem described, because it contextualizes the contents in everyday life, allows students to actively build knowledge and contributes to the development of communication and communication skills of joint work.

The experience described below was aimed at showing that the integration of PBL and the use of Information and Communication Technologies (ICT) favors the prominence of the student. By using a symbolic calculation system (MatLab) in the execution of routine tasks, the necessary space is achieved for the student to focus his efforts on more general mental processes, develop his reasoning ability and creativity, as well as another set of skills and capabilities that will serve you for your professional development.

\section{CONCEPTUAL FRAMEWORK}

\section{A. Problem-Based Learning (PBL)}

It is a teaching-learning method characterized by promoting self-directed learning and critical thinking, part of a problem (designed or outlined by the teacher) that the student must solve in order to develop skills and competencies previously defined. The problem situations on which the ABP is based are real-world scenarios, the teacher models them or adapts them to give the student the possibility to investigate or experiment on the nature of these phenomena or daily activities.

In [5], it is argued that the starting point for the acquisition and integration of new knowledge is to use problems. There are several ways to work with PBL, [6] summarizes the steps students should take for their application: (a) reading and analyzing the problem scenario, (b) brainstorming, (c) listing what is known, (d) and a list of what is not it is known, (e) make a list of what needs to be done to solve the problem, (f) define the problem, (g) obtain information and $(\mathrm{h})$ present results.

\section{B. Basic Mathematic}

Basic Mathematics is a subject taught in the first semester in most professional schools of the Peruvian university system. Among other topics, it deals with mathematical objects such as: real numbers, relationships, functions, vectors, and matrices. 
When developing matrix algebraic operations, students capture the logical sequence to perform operations without further difficulty except when the calculations are large, but when asked to analyze the information, they are confused and exposed wrong opinions.

To solve the analysis of the information will work on solving problems that will be modeled by matrices, such as a graphic figurative system, that represented reality graphically and symbolically to make the problem more understandable, it is intended so that the student manages to appropriate the concept.

\section{METHODOLOGY}

The experience was held at the Professional School of Mechanical Engineering of the National University of San Agustín de Arequipa (Peru) during the 2017-A period. The population under analysis consists of 30 students enrolled in the "Basic Mathematics" subject.

This study is part of a field investigation with a quasiexperimental design (a control group has not been included), quantitative and phenomenological type. Students to carry out the activities are organized based on cooperative learning techniques.

A questionnaire has been used to collect the students' perception of the experience.

\section{DESCRIPTION OF THE EXPERIENCE}

\section{A. Context}

The subject Basic Mathematics is taught in the first semester of the career; equivalent to 4 academic credits corresponding to 4 hours of theory and 2 hours of practice. In the development of the subject, in the theoretical hours the participatory master class has been used as a form of organization and in the practical hours some cooperative work activities were implemented.

In particular, PBL-based activities were implemented for the development of the topic "Operations with arrays and applications".

\section{B. Features}

The experience was conducted in 3 theoretical-practical sessions, communication between students and the teacher, as well as information management and survey were conducted through different functionalities of the Moodle platform (email, forum, wiki, file, task, survey, questionnaire, etc.).

The groups were formed on the basis of the principles of Cooperative Learning (CL). Using the grades obtained in the evaluation, each team was made up of a well-performing, one low-performing, and two mid-level students. With these premises, 5 teams were formed with 4 members and 2 teams of 5 members.

To organize group work, roles within the group were defined; following $[6,7]$ four roles were considered: coordinator, academic manager, editor-in-chief and creative manager. These roles were rotating, so that each team member was able to perform each of the defined roles.
To model the problems, the recommendations of [8], who say that an adequate problem to work from the ABP, should be based on real problems, preferably multidisciplinary, be related to the teaching objectives of the subject, to be open, topical, complex and appropriate to the cognitive and motivational level of students.

MatLab was chosen for the execution of calculations because of their availability in the computer lab and because the operations are expressed in a similar way as in mathematics.

The implementation of the virtual classroom followed the instructional design presented in [9].

\section{The Experience Stages}

1) Stage 1: Presentation of the theoretical basis and the characteristics of the work to be performed

Face-to-face session in which a didactic sequence was worked on to present the matrix operations (sum, difference, multiplication of a scalar by a matrix, multiplication of matrices).

In this sequence the concepts were presented, the operations were explained, exercises were solved and some problems were solved. To consolidate the work done, a link was configured in the virtual classroom through which they could access a set of 4 problems that had to be solved under the PBL methodology.

An additional 10 minutes were used to explain the cooperative characteristics of the work, the PBL and the formation of groups:

- The characteristics of a cooperative work, the functions of each of the roles within the group and the need to rotate the roles were explained.

- General information was given on the 8 steps to apply PBL.

- It was reported that some Moodle functionalities (forum, chat and wiki) that could be used to work the problems had been configured for each group.

- It was proposed that in the next face-to-face session one of the problems would be solved as an example.

All this information was placed in the virtual classroom of the Moodle platform, in addition material related to the ABP was placed. This decision was made taking into consideration of the results obtained in relation to the acceptance of the use of the platform [10] in previous work.

\section{2) Stage 2: Presentation and solution of the problem}

According to the schedule, a theoretical-practical class was targeted to the solution of one of the proposed problems.

\section{Problem Presentation}

Ana the secretary of the "Blue Earth" Research project is in charge of the purchase of the office material. 
She had received three catalogs of office supplies stores, before ordering the purchase you decide to do a price study to save.

Ana has to decide on a supplier, to do so she takes a sample, the prices of five items in the three suppliers and will estimate the expense she would have following last year's orders in the same month.

For the study, Ana considers the prices of: notebooks, pen boxes, spare parts of ink cartridges, staple boxes and thousands of Bond paper.

With the first supplier, the prices are $S / 15.00$ the notebooks, S / 30.00 Box of 50 Faber Castell Pens, S / 2.70 box of Staples 26/6 x 5000 Arty, S / 27.90 c / u HP 664 Tri-Color Ink SKU: 250893-1, S / $9.6075 \mathrm{~g}$ Bond A4 paper. 500 sheets

The second supplier has the prices S / 15.50 the notebooks, S / 30.50 Box of 50 Faber Castell Pens, S / 3.10 box of Staples 26/6 x 5000 Arty, S / 27.00 c / u Ink HP 664 Tricolor SKU: 250893-1, S / $9.8075 \mathrm{~g}$ Bond A4 paper. 500 sheets

The third supplier has the prices S / 13.80 the notebooks, S / 29.50 Box of 50 Faber Castell Pens, S / 3.20 box of Staples 26/6 x 5000 Arty, S / 27.60 c / u Ink HP 664 Tricolor SKU: 250893-1, S / $9.3075 \mathrm{~g}$ Bond A4 paper. 500 sheets.

Orders placed the previous year in the months of October, November and December are presented in Table I.

At this point the question was asked: What decision should Anne make?

\section{Problem solution:}

Students in class solve the problem posed. The teacher performs accompanying work, verifies that students play the assigned role, that they use the steps of the ABP as a guide that they actively participate by providing ideas for the solution of the problem.

After the job is complete, you must record it in a record that they are must upload to the wiki assigned to their group. The record should show that the first five steps of the PBL procedure have been developed.

The following describes what was worked by one of the groups. They queued the data in matrix form. They defined a price matrix; in the rows they placed the vendor data and in the columns the data of the item types (Fig. 1). Similarly, they defined an order matrix (Fig. 2) in which the data per month and the number of items of each type were placed in the rows.

TABLE I. ORDERS MADE

\begin{tabular}{|l|l|l|l|l|l|}
\hline Month & Notebooks & $\begin{array}{l}\text { Pens } \\
\text { box }\end{array}$ & $\begin{array}{l}\text { Ink } \\
\text { cartridges }\end{array}$ & $\begin{array}{l}\text { Staples } \\
\text { boxes }\end{array}$ & $\begin{array}{l}\text { Bond } \\
\text { paper }\end{array}$ \\
\hline Oct. & 11 & 5 & 5 & 4 & 14 \\
\hline Nov. & 12 & 1 & 8 & 8 & 18 \\
\hline Dec. & 15 & 8 & 10 & 12 & 20 \\
\hline
\end{tabular}

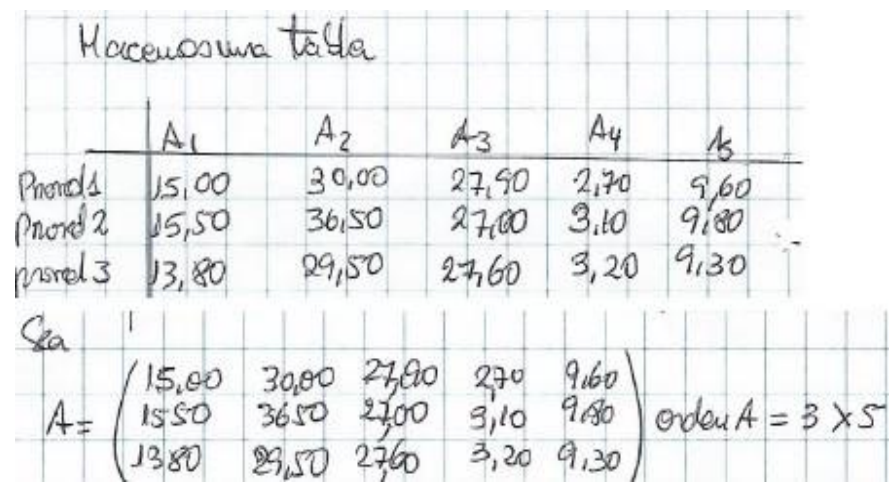

Fig 1. Price Matrix.

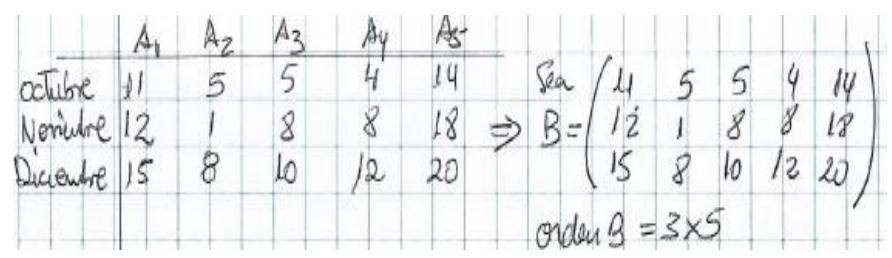

Fig 2. Data per Month and Prices Matrix.

To calculate the cost of those orders, with each vendor, they deduced that they would have to do a matrix multiplication. They had to check the compatibility of the dimensions, it had to be true that the number of columns in the first array was equal to the number of rows in the second. They needed to reason on which of the arrays should be reordered for the units to be consistent (matching prices and item numbers). Therefore, the product they made is shown in Fig. 3

Fig. 4 shows the results of the operation. The group concludes that it must be purchased from the third supplier.

Since the behavior of the groups was relatively homogeneous, students were asked to proceed in a similar manner with the other proposed problems. Each proposed problem dealt with a particular type of operations between arrays.

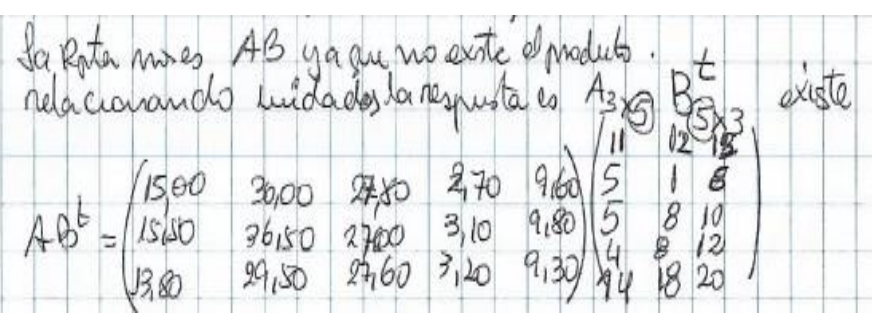

Fig 3. Matrix Product.

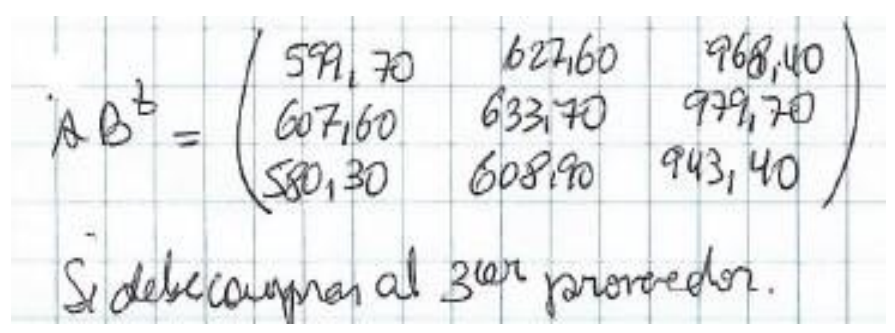

Fig 4. The Matrix Product Results. 


\section{3) Stage 3: The final report delivery}

Here the suggested final step for the PBL methodology was developed. For the resolution of the other proposed problems, a face-to-face session was combined with autonomous out-ofclass work.

The proposed problems related to different themes: graphs, rotation matrices and mixtures; consequently, the members of each group had to collect information from different sources: web browsers, literature of the subject, among others.

Partial progress was uploaded to each group's wiki. The process was followed up and feedback was given on the progress presented.

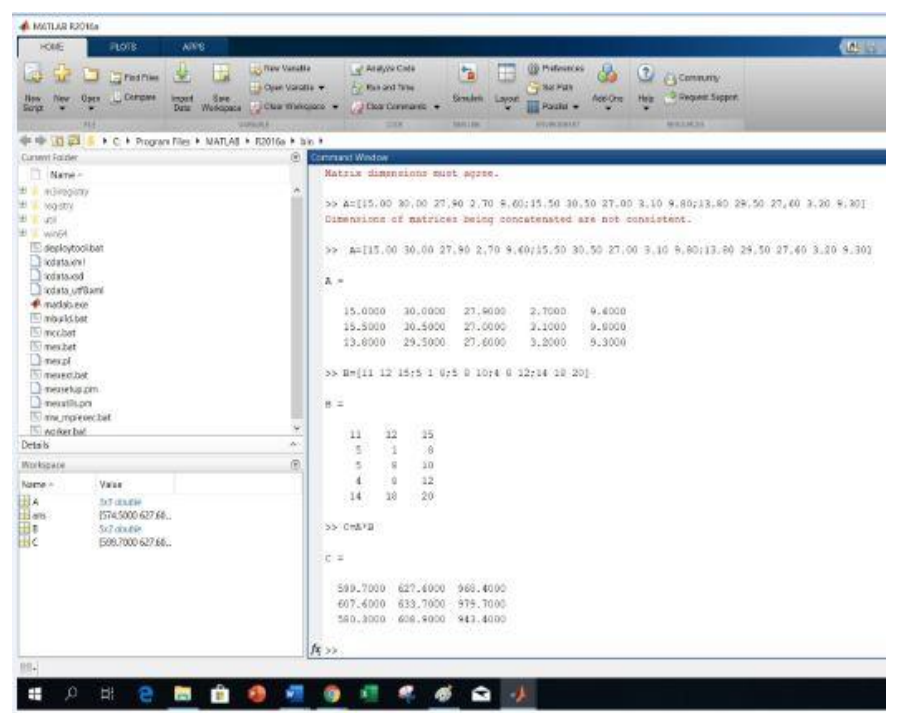

Fig 5. MatLab Check of Results of the Matrix Product.
Finally, each group produced a final report in which, taking into account the feedback received, the process followed and the results they had reached were allocated. Additionally, for the final report it was requested to check the results using MatLab. Fig. 5 shows the solution in MatLab for the problem described.

\section{4) Stage 4: The final report presentation}

A plenary session was scheduled for submission. In order for students to acquire practice in reporting in limited-time formats, they were asked to search for information about the "pecha kucha" format.

The plenary was held by assigning each group 7 minutes for the exhibition and 5 questions.

As there was the feeling that time had been very short, in the virtual classroom a P and R forum (questions and answers) was opened that is characterized because to participate it is necessary to issue an opinion first. Students were informed that everyone should participate at least once in this forum.

\section{5) Stage 5: Activity evaluation}

The evaluation of PBL's activity considered two aspects:

- Evaluation of group work: The final report was evaluated using a rubric (Table II, at the end of the document).

- Evaluation of individual learning: An evaluation was prepared through the "Questionnaire" functionality of the virtual classroom.

For the final qualification, weights were established for the different activities carried out: Process Evaluation (30\%), Final Report (30\%), Individual Learning (40\%).

TABLE II. RUBRIC TO EVALUATE PBL ACTIVITY

\begin{tabular}{|c|c|c|c|c|}
\hline Evaluation criteria & $\begin{array}{l}\text { Higher } \\
\text { (from } 18 \text { to } 20 \text { points) }\end{array}$ & $\begin{array}{l}\text { High } \\
\text { (from } 15 \text { to } 17 \text { points) }\end{array}$ & $\begin{array}{l}\text { Basic } \\
\text { (from } 11 \text { to } 14 \text { points) }\end{array}$ & $\begin{array}{l}\text { Low } \\
\text { (less than } 11 \text { points) }\end{array}$ \\
\hline Obtaining information & $\begin{array}{l}\text { Search, organize and } \\
\text { select information in a } \\
\text { relevant way }\end{array}$ & $\begin{array}{l}\text { Identify important information, } \\
\text { but omit some aspects. }\end{array}$ & $\begin{array}{l}\text { Locate the information, but it is } \\
\text { difficult to relate the different } \\
\text { facts. }\end{array}$ & $\begin{array}{l}\text { Search for the information, } \\
\text { but cannot contextualize it to } \\
\text { solve the problem }\end{array}$ \\
\hline Understanding & $\begin{array}{l}\text { Identify the main idea and } \\
\text { determine its purpose }\end{array}$ & $\begin{array}{l}\text { Find the main idea but do not } \\
\text { synthesize the information. }\end{array}$ & $\begin{array}{l}\text { It does not use all the relevant } \\
\text { information. }\end{array}$ & $\begin{array}{l}\text { It does not identify the main } \\
\text { ideas. }\end{array}$ \\
\hline Interpretation & $\begin{array}{l}\text { Contrast the information } \\
\text { and make inferences }\end{array}$ & $\begin{array}{l}\text { Analyzes the information, but } \\
\text { fails to relate aspects that lead } \\
\text { to a better interpretation. }\end{array}$ & $\begin{array}{l}\text { Analyze parts of the information, } \\
\text { but does not identify specific } \\
\text { aspects }\end{array}$ & $\begin{array}{l}\text { It makes no sense to the } \\
\text { information, then does not } \\
\text { interpret it properly. }\end{array}$ \\
\hline $\begin{array}{l}\text { Reflection and } \\
\text { assessment. }\end{array}$ & $\begin{array}{l}\text { Relate the information to } \\
\text { the problem. }\end{array}$ & $\begin{array}{l}\mathrm{He} / \text { she needs to organize his } \\
\text { ideas better and relate them to } \\
\text { the problem }\end{array}$ & $\begin{array}{l}\text { It stays on the literal level and } \\
\text { does not relate it to the problem. }\end{array}$ & $\begin{array}{l}\text { Read the problem, but do not } \\
\text { relate the information to a } \\
\text { possible solution. }\end{array}$ \\
\hline
\end{tabular}




\section{RESULTS AND DISCUSSION}

The results of the survey conducted in order to gather the perception of students, in relation to the experience of Problem-Based Learning, are shown in Fig. 6 (at the end of the text).

For the conduct of the survey, a questionnaire was designed that considered eight aspects that were valued using a three-tier Likert scale.

In the light of the results obtained, it is confirmed that the use of the methodology "Problem-Based Learning" enables students to assimilate and transfer concepts and develop thought strategies.

In the design of a problem-solving-based teaching sequence, it is not enough to apply the steps suggested by the methodology; certain fundamental objectives should be taken into account: (a) the assimilation of concepts and principles, (b) the ability to transfer to real problems, (c) the development of analysis and synthesis capabilities and (d) the development of strategies for the solution of Problems.

Applying a problem-solving methodology, supported by ICT tools, can favor some important aspects of the teachinglearning processes of Mathematic: student motivation, development and creativity, development of mathematical thinking and the achievement of meaningful learnings.

The study showed that students positively value the PBL methodology, $83 \%$ of them perceive that they favor their learning and about $79 \%$ agree with $[11,12]$ that the use of this allows the development of generic competencies such as reflection creativity and interpersonal communication.

In relation to the time allotted for the activity, only $45 \%$ of students perceive that the time was sufficient, which is explained by their lack of experience in working as a team; as students of the first university cycle, they bring with them the idea that working as a group means the non-systematic union of individual efforts.

On average, $60 \%$ agreed that good integration between theory and practice was verified, while around $65 \%$ agree that they were pleased with the methodology; however, only $52 \%$ stated that the methodology was accessible. This could be explained through resistance to the change in teaching methodology, a situation already discussed in [13].

Overall, the qualitative results have been quite satisfactory, results that match [14], experience in which the ABP methodology has been applied to enhance students' learning outcomes.

On the other hand, students suggest more activities where they can view the application of the contents.

Considering that students take their first year and the nature of the subject, it is difficult to find applications of some subjects, however, it is a challenging task that will try to fulfill for the next course.

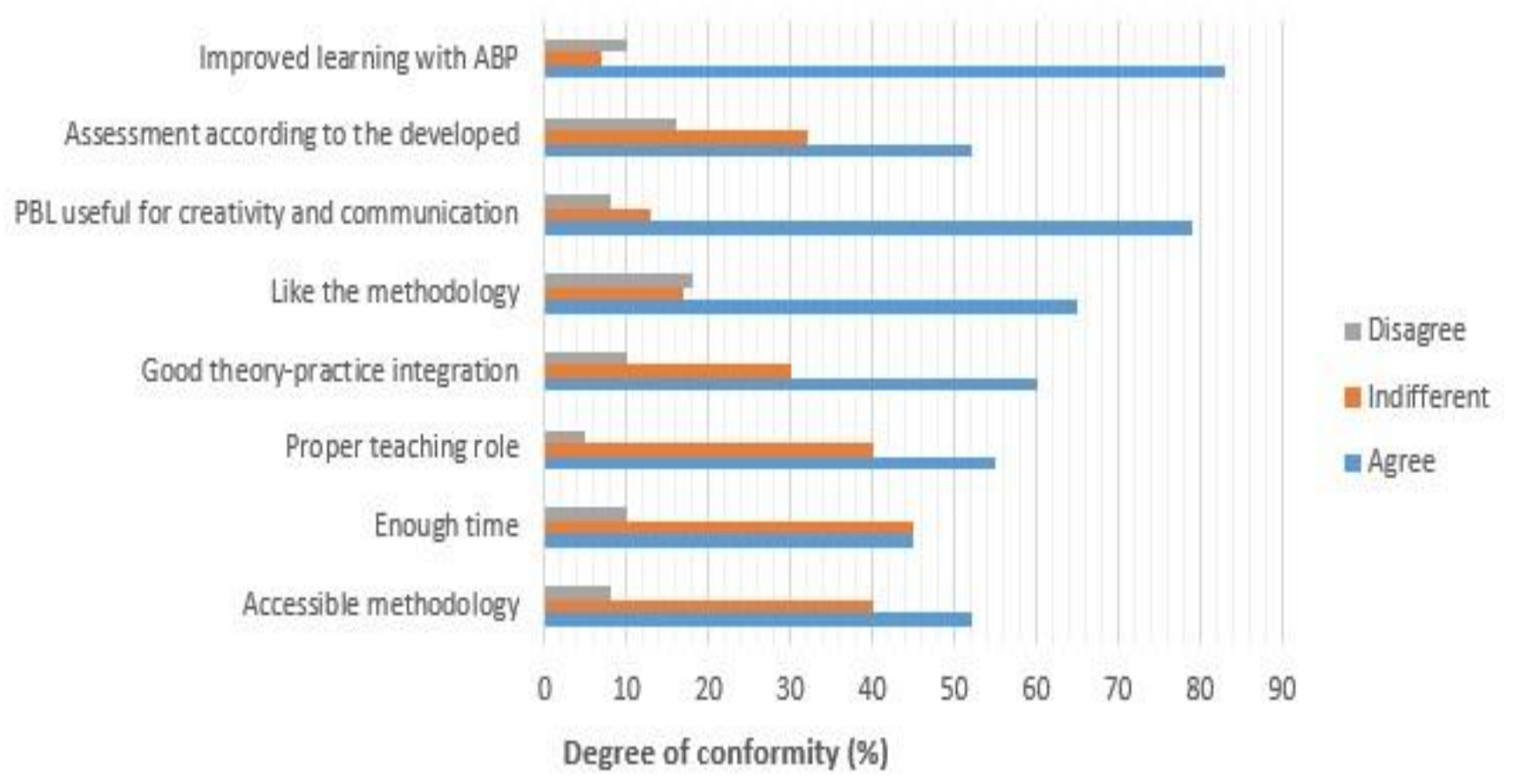

Fig 6. Opinion Survey Results. 


\section{CONCLUSIONS}

During the interaction process, students in addition to understanding and solving the problems recognized the applicability of the object of study and the need to work cooperatively.

Implementing an ABP activity to solve array operations application issues has helped students become familiar with various applications.

The results indicate a high degree of satisfaction with the work done and commitment to your learning process; which shows the need to change traditional methodologies in the teaching of Mathematics (professor-centered) to active methodologies (student-centered).

Problem-Based Learning is an alternative to the traditional methodology, which allows to evaluate the student's ability to solve situations comparable to real situations, bringing them closer to the professional profiles required by today's society.

\section{ACKNOWLEDGMENT}

We want to express the authors' our sincere gratitude to the National University of San Agustín de Arequipa for the support received for the realization of the proposal and we hope that the results will benefit the institution.

\section{REFERENCES}

[1] J. Kaput. "Transforming algebra from an engine of inequity to an engine of mathematical power by algebrafying the K-12 curriculum". Dartmouth, MA: National Center for Improving Student Learning and Achievement in Mathematics and Science. 2000.

[2] C. Kieran. "Algebraic Thinking in the Early Grades: What Is It?" The Mathematics Educator, 18(1), 139-151. 2004.

[3] C. Cowen. "A project on circles in space". En D. Carlson, C. R. Jonson, D. C. Lay, A. D. Porter, A. Watkins y W. Watkins (comps.) Resources for the teaching of linear algebra (pp. 59-70). Washington, Estados Unidos: Mathematical Association of America. 1997.

[4] J. Day. "Teaching linear algebra new ways". En D. Carlson, C. R. Jonson, D. C. Lay, A. D. Porter, A. Watkins y W. Watkins (comps.)
Resources for the teaching of linear algebra (pp. 71-83). Washington, Estados Unidos: Mathematical Association of America. 1997.

[5] A. García. "Aprendizaje basado en problemas: aplicaciones a la didáctica de las ciencias sociales en la formación superior". Ponencia en el II Congrés Internacional de DIDACTIQUES. Girona, Francia. 2010.

[6] N. Bedregal, "Cooperative learning using Moodle as a support resource: Proposal for continuous evaluation in operational research", Proceedings - International Conference of the Chilean Computer Science Society, SCCC. Volume 2017-October, 5 July 2018. DOI: 10.1109/SCCC.2017.8405131.

[7] N. Bedregal-Alpaca, D. Tupacyupanqui-Jaén AND V. CornejoAparicio. "Video and Cooperative Work as Didactic Strategies to Enrich Learning and Development of Generic Competences in numerical Methods". 2018 XIII Latin American Conference on Learning Technologies (LACLO). 2018. DOI: 10.1109/laclo.2018.00038

[8] A. Romero y J. García, "La elaboración de problemas ABP”, El aprendizaje basado en problemas en la enseñanza universitaria (pp. 3753). Murcia: Editum, Ediciones de la Universidad de Murcia, 2008.

[9] N. Bedregal, N. y D. Tupacyupanqui, "Integration of active methodologies and virtual classroom in the teaching-learning processes of Discrete Mathematics", Proceedings of the LACCEI international Multi-conference for Engineering, Education and Technology Volume 2018-July, 2018. DOI: 10.18687/LACCEI2018.1.1.81

[10] N. Bedregal-Alpaca. V. Cornejo-Aparicio, D. Tupacyupanqui-Jaén and S. Flores-Silva. "Evaluation of the student perception in relation to the use of the Moodle platform from the TAM perspective". Ingeniare. Rev. chil. ing. vol.27 no.4 Arica dic. 2019. DOI 10.4067/S071833052019000400707.

[11] C. Calpopiña and S. Bassante. "Aprendizaje basado en problemas, un análisis crítico". Rev Publicando. 2016;3:341-50.

[12] N. Bedregal-Alpaca, D. Tupacyupanqui-Jaen, M. Rodriguez-Quiroz, L. Delgado-Barra, K. Guevara-Puente and O. Sharhorodoska, "ProblemBased Learning with ICT Support: An experience in teaching-learning the concept of derivative," 2019 38th International Conference of the Chilean Computer Science Society (SCCC), Concepcion, Chile, 2019, pp. 1-7. DOI: 10.1109/SCCC49216.2019.8966396

[13] J. Vadillo, , I. Usandizaga, A. Goñi and M. Blanco. "Análisis de los resultados de la implantación $\mathrm{ABP}$ en un Grado de Ingeniería Informática". Actas del simposio-taller sobre estrategias y herramientas para el aprendizaje y la evaluación. 2015.

[14] L. Sarkady, L. Alveiro, M. Carrasco, M. Molina, M. Llanes, M. and M. Aguado. "Investigaciones educativas sobre enseñanza y aprendizaje de la Química”. 30.o Congreso Argentino de Química. 2014 